\title{
Uma abordagem de inspiração humanizadora para o projeto de habitação coletiva mais sustentável
}

\author{
A humanizing approach towards more sustainable \\ multifamily housing design
}

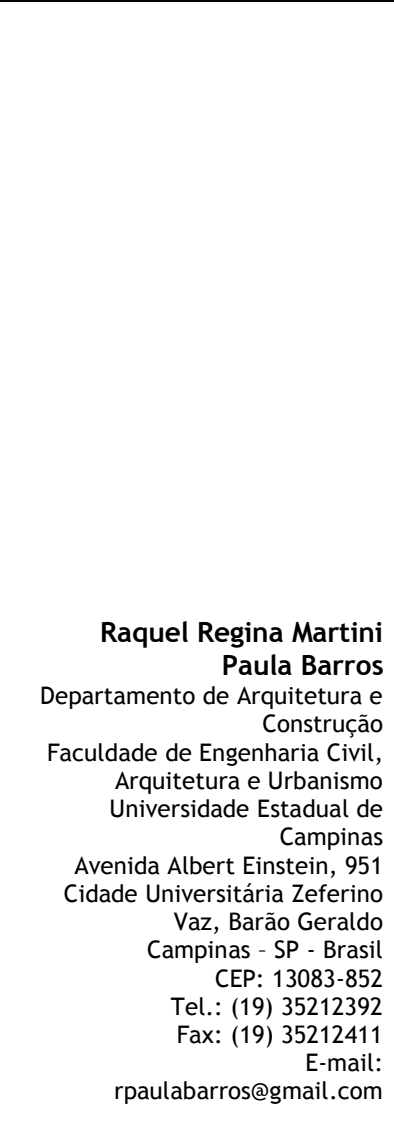

Sílvia Aparecida Mikami

Gonçalves Pina

Departamento de Arquitetura e Construção

Faculdade de Engenharia Civil, Arquitetura e Urbanismo Universidade Estadual de

Campinas

E-mail:

smikami@fec.unicamp.br

Recebido em 17/04/2010

Aceito em 20/07/2010

\section{Raquel Regina Martini Paula Barros Sílvia Aparecida Mikami Gonçalves Pina}

Resumo contribuição para o ato de projetar. Padrões selecionados, entre os identificados por Christopher Alexander e equipe em 1977, foram interpretados como parâmetros projetuais passíveis de serem abrangidos por conceitos humanizadores, cuja relevância foi verificada por meio da análise de um conjunto de projetos premiados. Tais conceitos requerem a compatibilização efetiva entre as diferentes possibilidades sugeridas individualmente pelos parâmetros projetuais e são igualmente fundamentais para a qualidade do projeto em seu todo. O caráter sintético e aberto da abordagem, somado às especificidades programáticas e locais, permite e recomenda outras contribuições para a consolidação de base humanizadora para o processo de projeto, fomentando o aprimoramento das soluções habitacionais coletivas mais sustentáveis.

Palavras-chave: Habitação coletiva. Processo de projeto. Humanização. Sustentabilidade.

\section{Abstract}

This study presents a design approach that relates humanizing concepts to the environmental quality of multifamily housing. The conception of a more humane and sustainable dwelling suggests interdisciplinary theoretical engagement as a contribution to the design process. Selected patterns among those identified by Christopher Alexander and colleagues in 1977 were interpreted as design parameters that can be comprised by humanizing concepts, whose relevance was verified through the analysis of a comprehensive set of award-winning designs. These concepts require effective compatibility among the different possibilities suggested by the design parameters, and are equally fundamental for design quality as a whole. The synthetic and open character of the approach, combined with programming and site specificities allow for and recommend further contributions towards the consolidation of a humanizing knowledge base for the design process that fosters the improvement of more sustainable multifamily housing solutions.

Keywords: Multifamily housing. Design process. Humanization. Sustainability. 


\section{Introdução}

As soluções ambientais para o enfrentamento dos desafios habitacionais e urbanos no Brasil requerem constante aprimoramento para maior sustentabilidade. As desigualdades sociais e a concentração de renda se manifestam espacialmente no território urbano. Empreendimentos de larga escala que priorizam o alto adensamento populacional em territórios negligenciados da periferia têm gerado impacto ambiental não condizente com os parâmetros aceitáveis, bem como dificultam o bem-estar físico e emocional dos usuários. Iniciativas bemintencionadas para áreas mais centrais também têm apresentado dificuldade em alcançar a almejada qualidade, especialmente aquela relacionada a um habitar mais humano e sustentável. A concepção desse tipo de habitar suscita engajamento teórico interdisciplinar como contribuição para o ato de projetar. Nesse sentido, o presente estudo propõe uma abordagem para o processo de projeto que relaciona conceitos humanizadores à qualidade ambiental do projeto de habitação coletiva a partir da análise de projetos.

Considera-se que abrigar plenamente a relação ambiente-comportamento no projeto da habitação coletiva inclui o resgate de um senso de lugar e de habitar e que a percepção arquitetônica aos fatores que interferem naquela relação é importante para o processo de projeto que almeja uma real sintonia aos anseios de uma comunidade e às qualidades do local. Contribuições seminais de estudos da relação ambiente-comportamento incluem Lynch (1960), Hall (1966), Sommer (1969) e Rapoport (1969). Entre essas, situa-se também a extensa obra de Christopher Alexander, tanto individual quanto coletiva, como investigação acerca das relações mútuas entre os seres humanos e o ambiente. Alexander et al. (1977) incorporam profundo conteúdo humanizador derivado da observação de atributos espaciais de lugares bemsucedidos e constitui o ponto de partida para este trabalho. Em parte, aquele conteúdo pode ser considerado de valor universal, dada sua conexão a necessidades humanas constantes. A partir da verificação dessas necessidades, Kowaltowski (1980) propõe princípios para a humanização em arquitetura. No Brasil, contudo, o potencial de contribuição daquele conteúdo humanizador para o processo de projeto parece subutilizado, especialmente no âmbito da habitação coletiva.

$\mathrm{Na}$ escala da implantação de conjuntos habitacionais, um grande número de fatores ambientais deve ser envolvido, de tal forma que possam interferir na qualidade de vida dos futuros usuários bem como ter impactos nos aspectos de sustentabilidade (KOWALTOWSKI et al., 2006), confirmando a necessidade de indicadores relacionados permearem os métodos de desenvolvimento de projetos. Lyle (1994) considera o processo de projeto como ferramenta fundamental para o reestabelecimento da conexão entre as pessoas e a natureza no ambiente construído e aborda os processos que dão suporte à vida de maneira inter-relacionada, a exemplo de como funcionam na natureza. Autores como Sattler (2007) e Alexander (2004) destacam o caráter holístico da sustentabilidade ao valorizar princípios que contribuem para o suporte à vida para além da pura contabilidade de recursos naturais. Argumentam pela necessidade de aprimoramento constante desde questões técnicas, como a conservação e utilização dos recursos renováveis, a manutenção e recuperação de ecossistemas, o uso de materiais apropriados e de ecotécnicas, até questões sociais e filosóficas, como construir em harmonia com o espírito do lugar, projetar com a natureza visando a uma relação saudável entre habitantes, comunidade e ambiente, e adotar a lógica do pensamento sustentável para a superação dos efeitos negativos de empreendimentos de larga escala.

Ao investigar o projeto de habitação coletiva de interesse social nos Estados Unidos da América e em países da Europa, Rowe (1995) observou que, após a Segunda Guerra Mundial, a orientação técnica moderna teria eliminado distinções espaciais importantes no âmbito da vida cotidiana, resultando em edifícios monótonos e residências indistintas. O caminho para um resgate qualitativo teria envolvido a promoção de conjuntos de menor porte e em âmbito local, na tentativa de melhorar a qualidade das condições e o significado expressivo da arquitetura na habitação. Apesar da defasagem temporal e desconsiderando-se as exceções, a mesma busca por um resgate qualitativo tem sido empreendida no Brasil, especialmente na cidade de São Paulo. Após a extinção, em 1986, da política habitacional do Banco Nacional de Habitação, políticas públicas locais e alternantes têm permitido experiências inovadoras, especialmente quando incluem concursos de projetos, ainda que poucos efetivamente tenham sido construídos.

Desde sua publicação, Alexander et al. (1977) têm recebido críticas significativas sobre o pouco conteúdo (científico) dos patterns (PROTZEN, 1978) à negação da legitimidade de um pluralismo de valores em arquitetura (DOVEY, 1990; SAUNDERS, 2002). Enquanto os patterns provavelmente possuem pouco conteúdo científico, eles demonstram uma conexão direta à vivência humana no ambiente construído. De fato, Dovey (1990) considera a abordagem da 
linguagem dos patterns uma base preciosa para a comunicação racional no projeto ambiental, enquanto Saunders admite a sintonia daquela obra à de outros pesquisadores considerados no meio acadêmico, os quais argumentam que as pessoas se sentem em harmonia quando mais próximas da natureza e no convívio social, também se referindo a estudos sobre a vida espontânea em comunidade e aos tipos de ambientes que a fomentam.

Assim, este estudo enfatiza a perspectiva para o ambiente habitacional que valoriza a relação entre conceitos de conteúdo humanizador e a qualidade ambiental de projetos avaliados. Parte de uma amostra local e abrangente de projetos premiados (BARROS, 2008) expressa uma dificuldade em se desvencilhar dos preceitos claros e bemintencionados do período áureo do modernismo local. Todavia, expressam uma percepção de desumanização, podendo incluir: edifícios monótonos; habitações indistintas, que não consideram uma diversidade de usuários; inadequação às atividades (metragem excessivamente reduzida, falhas no programa e agenciamento entre ambientes); e espaços externos residuais desintegrados. Ocorre a desconsideração de condicionantes locais que norteiam princípios da sustentabilidade social e ambiental que deveriam, em colaboração, permear o projeto urbano-arquitetônico a partir do entendimento das pessoas e do lugar, de modo a valorizar o entorno e sua ecologia, os espaços públicos, a convivência, a privacidade, o ar puro, entre outros. Almeja-se ainda contribuir para a estruturação de base humanizadora para o processo de projeto com vistas ao melhor atendimento do amplo espectro de necessidades humanas no habitar mais sustentável. A abordagem proposta pode ainda ser aplicada como instrumental de análise de projetos.

\section{0 desenvolvimento da pesquisa}

Ancorando-se em Groat e Wang (2002), pode-se dizer que, enquanto a pesquisa conduzida por Alexander et al. (1977) adotou estratégia do tipo qualitativa sob enfoque fenomenológico, ela também pode ser caracterizada como uma argumentação lógica no modo como os patterns formam redes de conexões e visam influenciar a ação projetual, bem como na coerência com que se opõem a atributos do modernismo quase que como num tratado discursivo.

Derivando daquela primeira argumentação, a presente pesquisa valoriza o conteúdo humanizador dos patterns bem como seu caráter pedagógico, que contribui para a desmistificação do processo de projeto por meio da explicitação das questões e das soluções de projetos. Considera-se também que a maneira como os patterns são apresentados em Alexander et al. (1977) não enfatiza a complexidade da linguagem, tampouco as conexões hierárquicas entre eles. Salingaros (2000) observa que uma coleção aleatória de patterns não conforma um sistema, portanto regras para a conexão entre patterns são necessárias para que se atinja coerência no projeto. Embora mencionada naquela obra, essa necessidade não foi enfatizada. Para o entendimento sistêmico dessas relações e conexões, o termo pattern deve ser traduzido e interpretado como "parâmetro projetual", a fim de enfatizar seu conteúdo e caráter propositivo, e não mais o caráter prescritivo comumente associado ao termo "padrão", em português.

A hipótese da pesquisa é que conceitos construídos a partir de uma seleção de parâmetros projetuais podem contribuir para a qualidade espacial do projeto de habitação coletiva com relação ao melhor atendimento de uma variedade de necessidades humanas. Além da obra de Alexander et al. (1977), a hipótese foi verificada por meio da investigação do potencial daquela identificação de parâmetros para a análise projetual sobre fontes documentais que apresentavam os projetos premiados, especialmente os periódicos nacionais de arquitetura e urbanismo. Também foram realizadas visitas aos respectivos locais, e dados complementares foram requisitados dos autores quando as informações disponíveis nas publicações eram insuficientes. Para o desenvolvimento da estrutura conceitual da estratégia projetual, elaborou-se uma série de procedimentos em processo dinâmico envolvendo a coleta, a descrição e a análise das informações, apresentados conforme se segue.

\section{Coleta e descrição dos dados}

Cerca de 60 parâmetros projetuais pertinentes ao tema habitacional foram selecionados entre os diversos identificados por Alexander et al. (1977).

Uma amostra abrangente de projetos premiados em âmbito local foi constituída, a fim de obter-se uma heterogeneidade de escalas de intervenção, organização especial, especificidades locais e localização no espaço-tempo, de modo a permitir a verificação de presença de um maior número de parâmetros. A amostra objeto de estudo representa uma coletânea de projetos até então indisponível. Inclui os projetos de habitação coletiva premiados no Estado de São Paulo no período de 1980 a 2005, construídos ou não, para diferentes faixas de renda de usuários, totalizando 35 projetos. Três tipologias edilícias foram identificadas, além da 
eventual mistura entre elas. Os projetos foram primeiramente agrupados por faixa de renda e em seguida de acordo com a área $\left(\mathrm{m}^{2}\right)$ do terreno. Da amostra de 35 propostas, 24 delas consistem de empreendimentos para habitação de interesse social (HIS) ou incluem uma porcentagem de unidades habitacionais (UH) destinadas para HIS, classificadas como pequeno e grande porte e apresentadas na Tabela 1.

Verificou-se e identificou-se a presença dos parâmetros nos projetos da amostra. Cinquenta e quarto parâmetros originais mais sete novos parâmetros foram reconhecidos. Dados quantitativos foram reunidos e relacionados em função de tipologia edilícia, faixa de renda, porte do empreendimento e localização no espaçotempo.

\section{Análise dos dados}

Extraiu-se o significado daquela seleção preliminar de parâmetros como fatores para o projeto habitacional conforme se segue: relação entre implantação e entorno construído e natural; relação entre tipologia edilícia e aspectos de conforto ambiental e privacidade; relação entre estrutura física e espaços de convívio (dimensões e metragem, variedade de pé-direito, senso de proteção, ambientes privilegiados, aberturas, sistema construtivo); zonas de transição entre rua e edificação e entre ambientes internos; encorajamento de expressividade (qualidades da luz natural e artificial, materiais de acabamento, cobertura).

Buscaram-se exemplos representativos dos parâmetros nos projetos por meio da percepção arquitetônica das configurações espaciais que proporcionam ambientes de qualidade. Verificouse que sua presença ocorria, em sua maioria, de modo não literal, endossando sua interpretação como parâmetros projetuais, e não padrões. Novos parâmetros foram identificados, de modo a melhor refletir o contexto sociocultural e ambiental local. Alguns deles consistem da combinação e adaptação de mais de um parâmetro original em Alexander et al. (1977) e correspondem ao olhar contemporâneo de habitação. A presença de maior ou menor quantidade de parâmetros, embora insuficiente para a explicitação da qualidade projetual, ofereceu suporte à análise dos projetos.

Os diferentes parâmetros variaram significativamente em relevância para a análise projetual, e foram identificados parâmetros-chave com um potencial de atratividade. São eles: diversidade de usuários; gradiente de privacidade no arranjo do conjunto; edifício melhorando terreno; e espaço externo positivo (ALEXANDER et al., 1977).

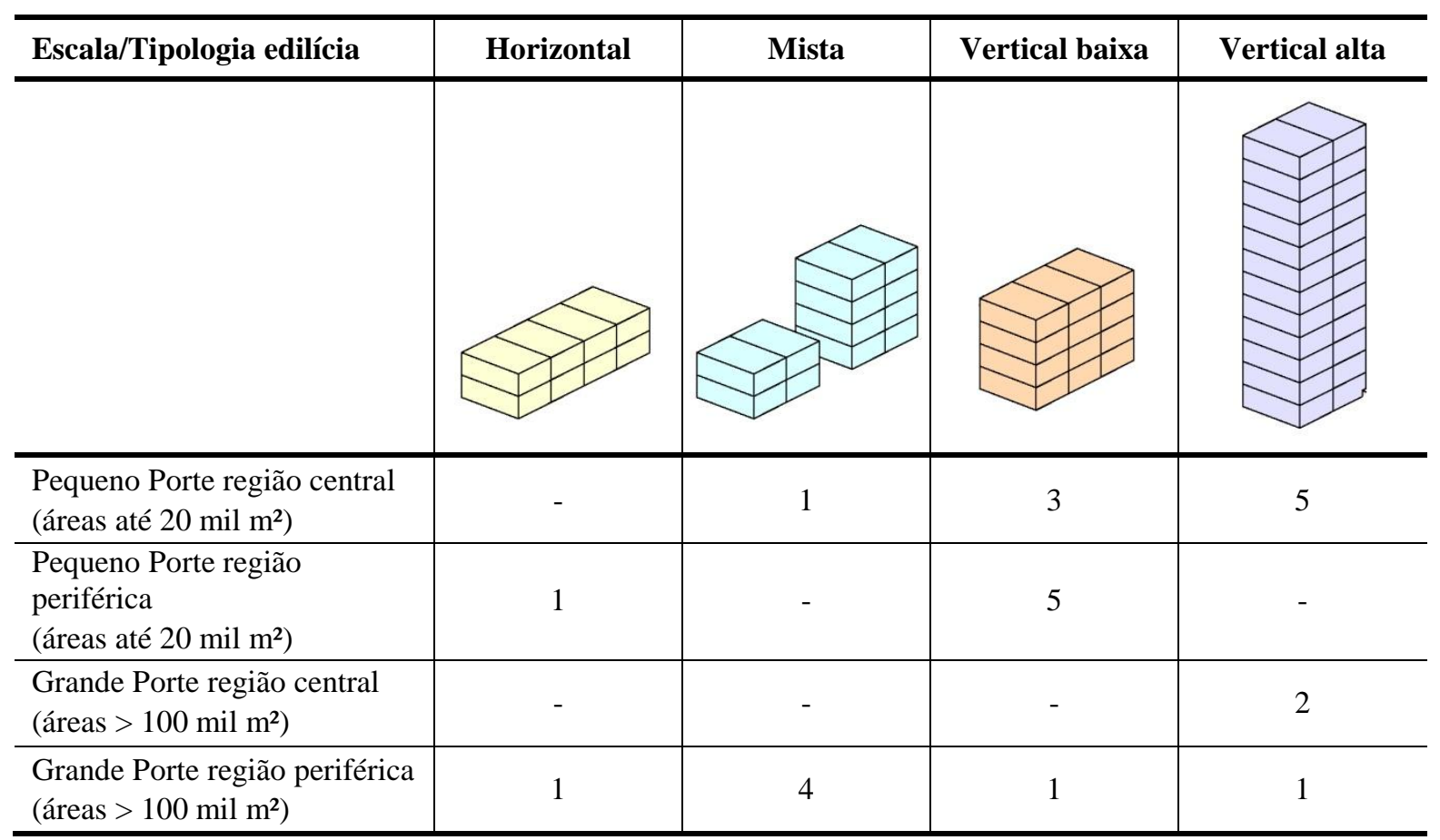

Tabela 1 - Distribuição das propostas de empreendimentos para HIS em relação às tipologias edilícias e à escala 


\section{Desenvolvimento de estrutura conceitual}

Os parâmetros-chave guiaram uma categorização primária dos parâmetros identificados sob os temas da sustentabilidade social e ambiental, vivacidade urbana, identidade e privacidade, que abrangem as necessidades humanas consideradas pertinentes, sobretudo às dimensões psicossociais e ambientais. $\mathrm{O}$ potencial de atratividade dos parâmetros-chave permitiu a configuração de associações e conexões entre parâmetros que eventualmente se sobrepõem àquela categorização primária. A relevância das associações entre parâmetros para a análise projetual sugeriu o desenvolvimento de estrutura conceitual. O conteúdo dos conceitos propostos foi também relacionado a pesquisas afins realizadas por outros autores, reforçando sua validade.

Evidenciou-se a relação entre os conceitos propostos e a qualidade espacial da amostra de projetos por análise narrativa. A afinidade aos conceitos propostos foi fundamentada na compreensão da qualidade projetual e sinalizada por uma maior ou menor quantidade de parâmetros.

\section{A abordagem de inspiração humanizadora}

Considera-se a obra de Alexander et al. (1977) imbuída de profundo conteúdo humanizador, a partir de extenso estudo de campo em que se observaram as características ambientais de lugares bem-sucedidos. Os espaços configurados refletem a interdependência de atributos que afetam os modos de ocupação e a percepção de significados. $\mathrm{O}$ enfoque fenomenológico para as pesquisas ambiente-comportamento é exposto por Graumann (2000) como relacionado ao significado investido por uma coletividade em lugares e edificações. Graumann salienta que, por meio da vivência individual e coletiva, os seres humanos se apropriam do ambiente, que se torna incessantemente humano e mutável, o espaço vivido. Assim, a arquitetura cria o lugar para a existência humana abrigando as relações interpessoais em suas diversas modalidades de apropriação do espaço. A partir da verificação da representação de necessidades humanas, Kowaltowski (1980) propõe princípios para a humanização em arquitetura em termos da constância de necessidades sensoriais de privacidade, territorialidade, segurança, orientação espacial e estética. Coelho (2007) valoriza a perspectiva de um habitar humanizado positivamente marcado pelas pessoas e influenciador de sua vida individual, gregária e cívica. Entre as linhas de investigação que conduz, aborda uma perspectiva ecológica e humana ampla, que considera a importância do lugar como sítio próprio e identidade específica, da proteção e do papel protagonista da natureza e do verde urbano.

Nesse sentido e como contraponto àquela observação de desumanização presente em parte dos projetos habitacionais da amostra, propôs-se a abordagem de inspiração humanizadora detalhada em Barros (2008) e Barros e Pina (2009a). A partir da extração do significado da seleção preliminar de parâmetros projetuais como fatores para o projeto de habitação coletiva, obtiveram-se os seguintes tópicos: relação implantação - entorno construído e natural; relação tipologia edilícia - aspectos do conforto ambiental e privacidade; relação estrutura física - espaços de convívio (áreas, pés-direitos, senso de proteção, ambientes privilegiados e aberturas, sistema construtivo); relação exteriorinterior e zonas transição entre ambientes internos; encorajamento da expressividade (qualidades da iluminação natural e artificial, materiais de acabamento, cobertura). As necessidades humanas foram consideradas como pertencentes à esfera psicossocial e ambiental no universo da habitação coletiva desde a escala da implantação até a escala da UH e incluem a vivacidade urbana, diferentes graus de privacidade e envolvimento comunitário, segurança, legibilidade, identidade, senso de proteção e estímulos sensoriais. A abordagem proposta relaciona-se especialmente aos princípios da sustentabilidade social e ambiental, que, em colaboração, deveriam permear o projeto urbanoarquitetônico a partir do entendimento das pessoas e do lugar.

Projetar o ambiente construído de modo a reduzir o impacto aos sistemas de suporte à vida nas cidades e promover o bem-estar compreende considerar a relação ser humano-ambiente como processo interativo. Como enfoque que pretende contribuir para a contemplação da ampla gama de necessidades humanas, visualiza-se na abordagem aqui proposta interface entre a humanização da arquitetura na habitação e princípios da sustentabilidade, visto que constitui iniciativa que incentiva a consideração mais consciente no processo projetivo de conceitos que podem contribuir para o desenvolvimento sustentável. Sattler (2007) introduz princípios projetuais norteadores que visam desde a redução dos impactos ambientais até a concepção de lugares e edificações que propiciem completo bem-estar físico e mental, buscando contemplar a todos os sentidos humanos. Enriquecer o habitat humano sem prejuízo ao habitat natural envolve, para Sattler (2007), um conjunto de princípios 
norteadores que incluem o caráter holístico, a observância às relações sistêmicas entre processos ou fluxos e a interdisciplinaridade. Abrange enfoques variados, científicos e não tão científicos, que podem contribuir para a contemplação do vasto leque de necessidades humanas - físicas, cognitivas, sensoriais, emocionais e, quando possível, espirituais - no ambiente construído.

Em vista da relevância das associações entre parâmetros projetuais foram propostos conceitos de caráter propositivo. Os conceitos foram arranjados em duas categorias principais, senso de urbanidade e senso de habitabilidade, cada qual focada ora mais diretamente no arranjo territorial, ora na escala da edificação.

\section{O senso de urbanidade}

O senso de urbanidade se refere à escala da implantação das edificações. Essa categoria conceitual para o projeto de habitação coletiva visa proporcionar a vivacidade urbana que pressupõe o combate à setorização excessiva de usos, à segregação social e à dificuldade de locomoção. Inclui ainda a percepção de um sentido de lugar em sintonia com o entorno, a partir da conformação e da articulação dos espaços externos e das funções psicológicas de orientação e identificação. A sensibilidade ao ambiente construído e natural existente, aliada aos recursos espaciais específicos e aos parâmetros para a sustentabilidade social (diversidade de usuários e de faixas de renda, uso misto, valorização da circulação de pedestres), contribui para a conectividade espacial, legibilidade e identidade.

A sobreposição de relações socioambientais no tecido urbano de estrutura complexa permite a conectividade espacial e a interação social. O tema encontra respaldo teórico nos trabalhos de Alexander (1966) e Carmona (2001), entre outras obras. A preocupação com lugar e significado, o conceito de genius loci e a percepção de uma imagem ambiental encontram suporte, entre outros, em Norberg-Schulz (1976).

Essa categoria abrange três subcategorias de conceitos, apresentadas a seguir. Alguns dos principais parâmetros projetuais incorporados aos conceitos encontram-se ilustrados nas Figuras 1 a 3.

\section{Sensibilidade ao ambiente construído e natural existente}

Dentro da perspectiva da sustentabilidade predominantemente ambiental, este conceito intenciona preservar, acentuar e melhorar as qualidades do lugar a partir de uma visão do todo, em que o projeto procura contribuir para o caráter da vizinhança. Para essa qualidade contribuem as características irregulares do solo e permeabilidade, a topografia, o formato do terreno, a vegetação, a insolação, as vistas, bem como a presença de interfaces permeáveis entre terreno e entorno entrelaçando caminhos, lugares e ambientes de transição ao longo dos limites. Conjuntos organizados espacialmente de diversas maneiras, desde que conformando espaços externos positivos (de forma distinta e de igual importância à forma das edificações ao redor), esforçam-se por atender a especificidades e elementos naturais e construídos do terreno e entorno. $\mathrm{O}$ desenho urbano excessivamente abstrato prejudica o entrelaçamento das edificações ao lugar, podendo resultar em configurações segregadoras, que não permitem uma rede de espaços externos positivos permeáveis.

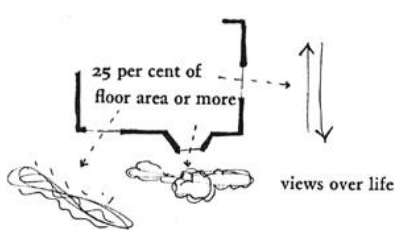

(a) Vistas

(192-windows overlooking life)

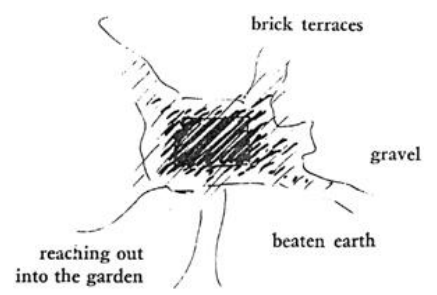

(b) Entrelaçamento entre edificação e lugar (168-connection to the earth)

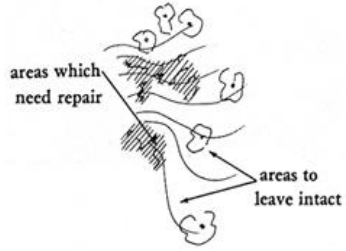

(c) Edificação melhorando terreno (104-site repair)

Fonte dos croquis: Alexander et al. (1977).

Nota: Informação entre parênteses em itálico: número e nome dos patterns originais

Figura 1 - Parâmetros projetuais do conceito "sensibilidade ao ambiente construído natural e existente" 


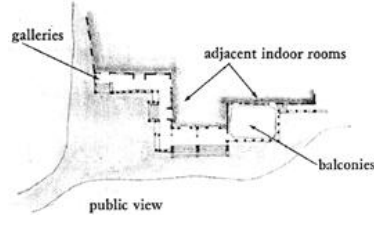

(a) Ambientes semiabertos ao longo dos limites

(166-gallery surround)

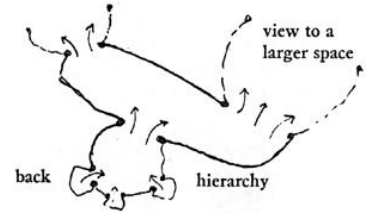

(b) Hierarquia entre espaços externos

(114-hierarchy of open space)

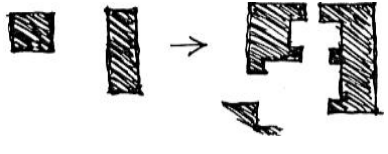

(c) Espaço externo positivo

(106-positive outdoor space)

Fonte dos croquis: Alexander et al. (1977).

Figura 2 - Parâmetros projetuais do conceito "conectividade, legibilidade e sustentabilidade social"

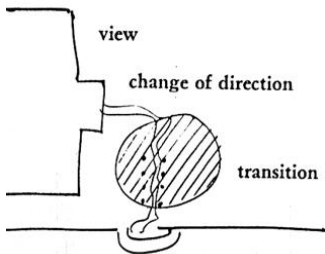

(a) Transição na entrada

(112-entrance transition)

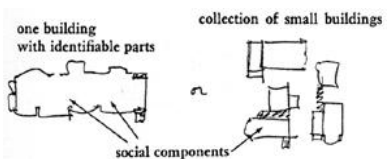

(b) Edificação como complexo

(95-building complex)

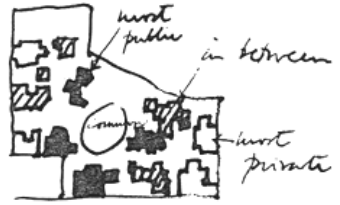

(c) Gradiente de privacidade no arranjo do conjunto (36-degrees of publicness)

Fonte dos croquis: Alexander et al. (1977).

Figura 3 - Parâmetros projetuais do conceito "identidade"

\section{Conectividade, legibilidade $\mathrm{e}$ sustentabilidade social}

Visando à concepção de projetos integrados na escala do bairro em continuidade com a malha urbana existente, este conceito propõe um desenho urbano que estruture e estabeleça hierarquia entre espaços externos positivos do conjunto e entre estes e o sistema maior de espaços externos do tecido urbano, proporcionando melhor distribuição da acessibilidade. A conexão dentro-fora e a legibilidade são proporcionadas por meio de fronteiras permeáveis das arcadas, galerias, terraços e escadas abertas de acesso, aliadas a estruturas formais que geram um alto grau de conformação dos espaços resultantes de edificações com recuos laterais e frontais reduzidos ou nulos. Formatos diferenciados de percursos podem incentivar a permanência ou a contemplação e configurar pátios internos e conjunto de entradas similares. Quando da ausência de espaço externo coletivo no conjunto, fronteiras permeáveis estabelecem relação mais direta com a rua. A vivacidade urbana é incentivada por diversidade de usuários e de faixas de renda, oferta de tipologias, dimensões e programas de moradia variados, que ajudam a sustentar atividades de lazer, comerciais e de serviços.

\section{Identidade}

A identidade para conjuntos e UHs individuais que abrangem diversidade de usuários pode se expressar, entre outros, por gradiente de privacidade no arranjo e agenciamento do conjunto. A demarcação de conjunto de entradas e as transições no espaço físico da entrada das UHs contribuem para sua identidade. A vegetação também pode conformar e distinguir espaços. Variações modestas no relevo das superfícies, bem como no layout da cobertura, expressam partes identificáveis como coleção de edifícios menores conectados. Eventuais contrastes no perfil geral da edificação podem enfatizar partes principais ou distintas, a entrada do conjunto e de espaços coletivos.

\section{0 senso de habitabilidade}

O senso de habitabilidade contempla os conceitos referentes à escala da edificação e das UHs em si. Esta categoria conceitual para o projeto de habitação coletiva busca proporcionar, a partir do atendimento de necessidades básicas de conforto 
ambiental e de adequação às atividades domésticas, um sentido de habitar que preencha as necessidades de refúgio, isolamento, convivência, ordem e variedade. Para tanto, os conceitos propostos enfocam questões como a relação entre tipologias de UHs e de agregação entre elas e aspectos de conforto ambiental e privacidade, e a relação entre estrutura física e espaços de convívio, de modo que a forma e as proporções dimensionais horizontais e verticais dos ambientes priorizem a adequação às necessidades de uso, convívio e proteção, e não uma racionalidade construtiva reducionista. Também envolve atenção para as zonas de transição e agenciamento entre ambientes internos, almejando um gradiente de intimidade doméstico eficiente, legível e permeável, o caráter e atributos sensoriais da iluminação natural e artificial, materiais de acabamento e cobertura, e, por fim, a oferta de opções de moradia para usuários diversos e suas implicações para o

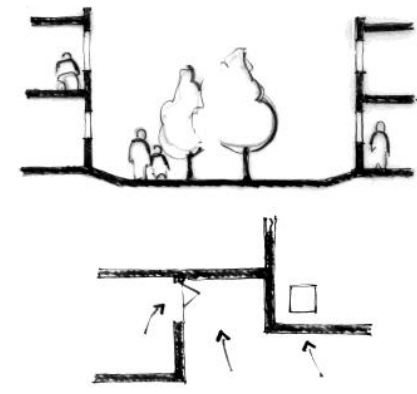

(a) Estratégias para privacidade-N3 sistema construtivo, aspectos da manutenção (reparos), adaptabilidade e expansão.

A relação entre organização espacial e aspectos do conforto ambiental e privacidade encontra suporte teórico em Sherwood (1994). Já os subsídios para o sentido de lar como permanência protegida se encontram em Norberg-Schulz (1976, 1983) e Kowaltowski (1980), entre outros. O gradiente de intimidade, as expressões de centralidade e verticalidade e a expressividade sensorial são estudados principalmente por Bloomer e Moore (1978) e Heschong (2002). A oferta de opções de moradia e as implicações mencionadas acima são também pesquisadas por Schneider e Till (2005).

Esta categoria conceitual abrange três subcategorias de conceitos, apresentadas a seguir. Alguns dos principais parâmetros projetuais incorporados aos conceitos encontram-se ilustrados nas Figuras 4 a 6.

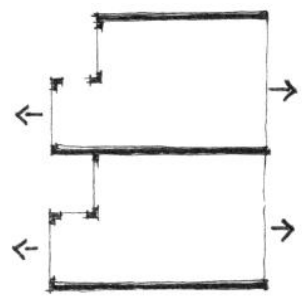

(b) Unidades agregadas com mais de uma orientação-N2

Fonte dos croquis: Barros (2008).

Figura 4 - Parâmetros projetuais do conceito "harmonia espacial: relação entre conforto ambiental e privacidade"

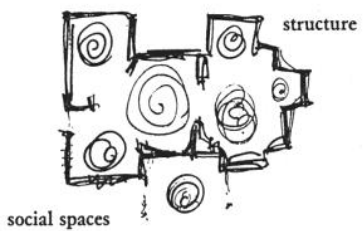

(a) Espaço físico congruente ao espaço de convívio

(205-structure follows social spaces)

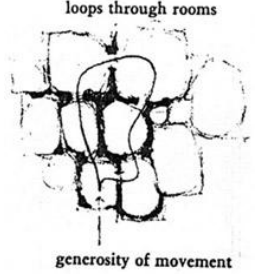

(b) Circulação interativa

(131-the flow through rooms)

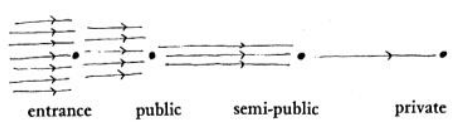

(c) Gradiente de intimidade

(127-intimacy gradient)

Fonte dos croquis: Alexander et al. (1977).

Figura 5 - Parâmetros projetuais do conceito "Sentido de Lar" 


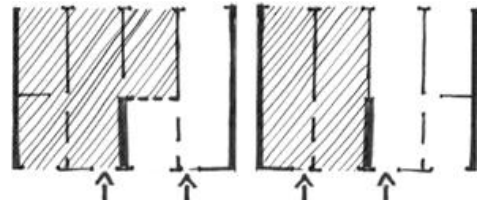

(a) Flexibilidade de uso-N5

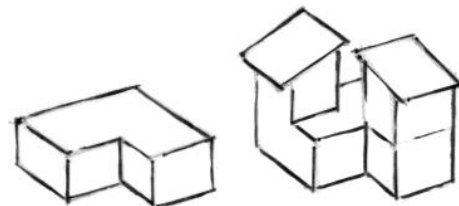

(b) Possibilidade de expansão-N6

Fonte dos croquis: Barros (2008).

Figura 6 - Parâmetros projetuais do conceito opções e flexibilidade

\section{Harmonia espacial: relação entre conforto ambiental e privacidade}

A implantação da edificação e espaço circundante, as diferentes possibilidades de agregação entre UHs, bem como o formato destas para o melhor aproveitamento da luz e ventilação naturais têm implicação no gradiente de intimidade das UHs. O enfoque da eficiência energética aos olhos da sustentabilidade ambiental orienta uma série de estratégias específicas que almejam a autonomia das edificações, podendo evitar a necessidade de outros recursos tecnológicos ou mesmo torná-los mais eficientes. Entre aquelas possibilidades de agregação, a opção por alas de forma alongada e estreita, horizontal ou verticalmente, facilita a obtenção de mais de uma orientação para as UHs e também o gradiente de intimidade. Porém, a agregação de UHs sobrepostas no sentido longitudinal com esse formato alongado acarreta deficiência luminosa, que pode ser resolvida com recursos como, por exemplo, afastamentos parciais entre UHs ou optando-se pela agregação das paredes laterais menores e não maiores (sentido transversal e não longitudinal). A obtenção de mais de uma orientação para UHs agregadas, especialmente em conjuntos de organização espacial adensada, acarreta a necessidade de outras estratégias conjuntas para o alcance da privacidade (especialmente visual) entre UHs confrontantes ou entre UHs e a rua. Por exemplo, a observação da distância entre UHs que se abrem uma para a outra, a criação de minipátios reservados para parte das aberturas, o uso de claraboias, janelas altas, vidro corrugado ou translúcido, elementos opacos posicionados em ângulo em relação à abertura, elementos vazados, venezianas sanfonadas ou brises articulados controláveis pelos usuários, vegetação, desnível de piso entre passeio e UH. Salienta-se que o uso das estratégias para privacidade propostas deve se dar com cautela a fim de não constituir emenda para possíveis falhas na concepção projetual. Vale também ressaltar a importância destas estratégias especialmente para as UHs térreas que, apesar de enfrentarem maiores desafios para o alcance da privacidade, são necessárias para o bom entrelaçamento do conjunto ao lugar.

\section{Sentido de lar}

Tem como premissa a criação de UHs que ofereçam adequação ao uso - as atividades devem guiar a estrutura física e não o contrário - e gradiente de intimidade através de diferenciação física (conformação e dimensões horizontais e verticais) que possibilite interação social bem como senso de proteção. Expressões de centralidade e verticalidade representam extensões da identidade e orientação corporal humana no ambiente e se traduzem por áreas de encontro centrais, visíveis e ladeadas por fluxos de passagem, incluindo a eventual escada que distribui as atividades verticalmente para fora do centro, acarretando uma boa distribuição e agenciamento entre ambientes. Os limites da habitação devem ser permeáveis criando zonas de transição através de diferenciações no percurso e criação de ambientes de entrada, terraços semielevados, varandas, saliências que conformam ambientes de contemplação, e outros recursos que visem tanto a comunicação como a privacidade, incluindo as estratégias já descritas. As aberturas, sua localização, dimensão e tipo, além de interferirem na adequação luminosa às diferentes atividades internas, interferem também na possibilidade de controle do gradiente de luminosidade e privacidade pelos usuários e na exploração do contraste luminoso e de vistas para o exterior que podem contribuir para a orientação e agradabilidade do percurso entre ambientes.

\section{Opções e flexibilidade}

Além de uma maior oferta tipológica e atenção aos aspectos de manutenção (reparos), o projeto de habitação coletiva pode também considerar a possibilidade de flexibilidade de uso ou de futuras expansões a fim de atender a usuários diversos. Porém, a planta livre que objetiva a fusão dos espaços pode levar ao caos ou à incongruência aos espaços de convívio, perda do gradiente de intimidade incluindo perda de privacidade visual e ou acústica. Para que a UH possa crescer ou ser alterada sem perda de coerência faz-se necessária definição clara de meio organizacional que reconheça partes primárias e secundárias, a fim de preservar determinadas propriedades espaciais e 
qualidades requeridas. Sistemas construtivos e materiais adequados precisam ser enfocados nas diferentes situações da construção. Diversos parâmetros projetuais em Alexander et al. (1977) incentivam a multifuncionalidade ou flexibilidade espacial desde que se garanta a congruência entre estrutura física e espaço social. O conceito aqui proposto não exclui a possibilidade de uso de sistemas e materiais industrializados: acredita-se que, se a racionalidade construtiva for usada como meio e não como fim, ou seja, não implicar um reducionismo ao projeto, pode ajudar na flexibilidade dos espaços e deve ser incorporada no processo de projeto de habitação coletiva. Experiência recente construída no Chile é exemplar do emprego da racionalidade construtiva a favor da qualidade ambiental da moradia social (FERNANDES, 2008). Quanto à possibilidade de expansão, em geral, nos projetos de HIS a exiguidade de área das UHs individuais que precisam atender a famílias muitas vezes numerosas é a principal causa para a necessidade de expansão das UHs. Projetos que já ofereçam variedade de programas de moradia, algumas já com maior generosidade de área por UH, visando a uma abrangência maior de usuários em diferentes fases da vida, podem diminuir a necessidade de modificações e ampliações futuras.

Salienta-se que os conceitos propostos requerem a compatibilização efetiva entre as diferentes possibilidades sugeridas individualmente pelos parâmetros projetuais e que as categorias "senso de urbanidade" e "senso de habitabilidade" são igualmente fundamentais para a qualidade do projeto como um todo, expressando basicamente mudança de escala: o conceito "sensibilidade ao ambiente" desdobra-se, na escala da UH, no conceito "harmonia espacial", e assim sucessivamente.

\section{Os projetos na perspectiva dos conceitos humanizadores}

Considera-se pertinente aplicar a abordagem humanizadora à análise e reflexão projetual da amostra em Barros (2008), ainda que brevemente e a título de ilustração.

Entre os projetos de habitação coletiva da amostra, encontram-se aqueles resultantes dos oito concursos para empreendimentos de HIS (ou que incluem uma porcentagem para HIS) entre $1980 \mathrm{e}$ 2005. Sobre estes se desenvolvem aqui algumas considerações, especialmente sobre os cinco concursos propostos para a cidade de São Paulo, dada sua representatividade. Considera-se que a maior parte das propostas para o "Concurso Nacional de Projetos para Habitação Popular", de 1990, apresenta sintonia ao enfoque dos conceitos humanizadores, especialmente ao senso de urbanidade. Apreende-se uma sensibilidade ao contexto socioambiental existente e uma valorização da articulação entre os espaços de uso público e coletivo, sendo que, à exceção dos demais concursos da amostra, parte das propostas foi efetivamente construída. Já nos projetos mais recentes, a saber, os vencedores dos concursos "Habitasampa" para as áreas Barra Funda e Assembleia e "Prêmio CAIXA-IAB", ambos de 2004, constata-se na maior parte das premiações uma priorização do melhor aproveitamento construtivo em detrimento dos valores incorporados à abordagem humanizadora proposta. Também se pode constatar menor afinidade à abordagem naqueles projetos para áreas de grande porte, como nos projetos vencedores do "Concurso de Ideias para um Novo Centro", de 1996, e no "Concurso Nacional para Projeto Urbano Bairro Novo", de 2004. Incluem-se, também, duas das propostas para o "Concurso Habitar com o Ambiente", promovido pela CDHU em 1994 para área de grande porte na periferia da cidade de Itatiba, que se situa na região macrometropolitana da capital.

Com relação ao conceito "sensibilidade ao ambiente construído e natural existente", as propostas para o referido concurso em Itatiba (Figura 7) apresentam configurações reveladoras. A área de cerca de 200 mil metros quadrados era, à época, parcialmente tomada por mata natural densa e eucaliptos. Em sua maior parte de topografia íngreme, está representada apenas a porção mais alta do terreno, passível de ocupação habitacional. A proposta (a) propõe complexo concentrado, com lâminas extensas dispostas radialmente à praça projetada, priorizando a circulação horizontal de acesso aos pavimentos em detrimento das possibilidades que o lugar e sua topografia proporcionavam. Os espaços externos são demasiadamente indistintos, não conformando espaços positivos, e um grande estacionamento periférico distancia o possível vínculo com o bairro consolidado. Já a proposta (b) apresenta caráter mais integrado ao entorno de vistas privilegiadas, entrelaçando uma variedade de caminhos e espaços externos em articulação. A implantação e o traçado das vias são posicionados em harmonia com as curvas de nível, o que contribui para o escoamento natural das águas pluviais e para uma implantação de menor impacto. As características do lugar são consideradas no todo, contribuindo, assim, para seu aprimoramento. 


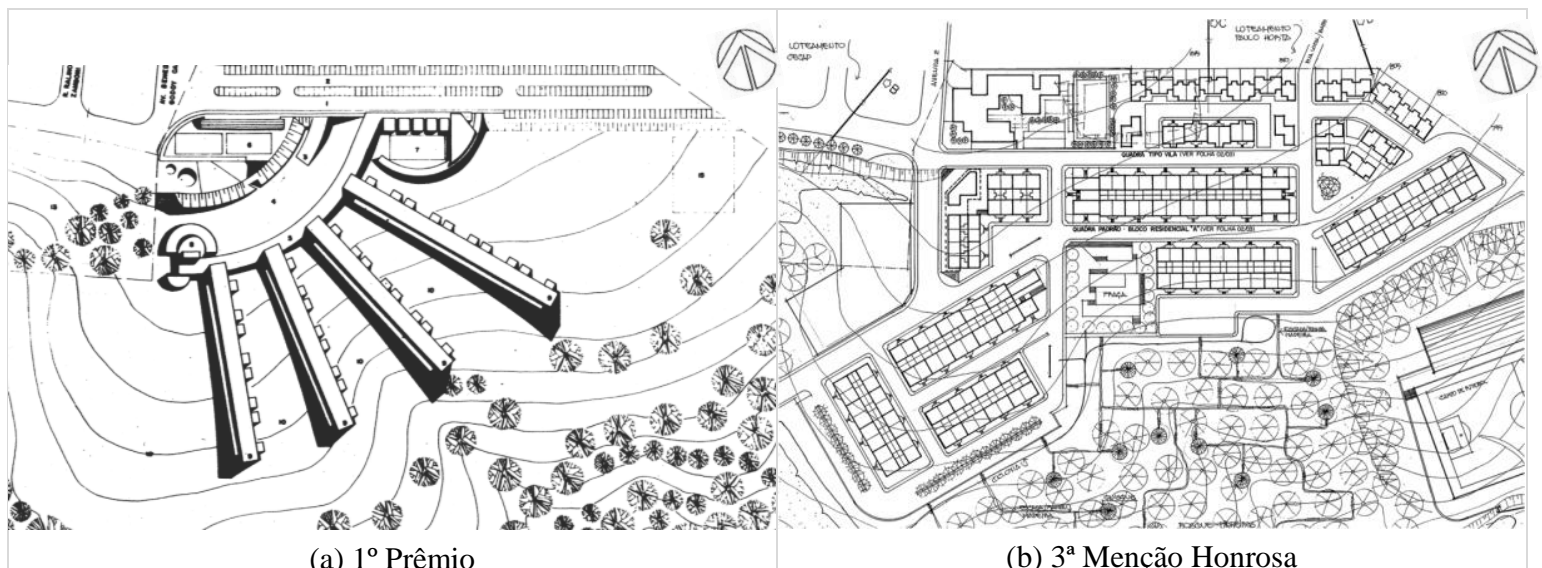

Fonte: (a) Padovano (1994); e

(b) Dados cedidos pelo autor do projeto.

Figura 7 - Trecho da implantação: Concurso Habitar com o Ambiente

Quanto ao conceito "conectividade, legibilidade e sustentabilidade social" em projetos do concurso Bairro Novo (Figura 8), observa-se uma falta de afinidade na proposta (a), detalhada em Barros e Pina (2009b). O reticulado cartesiano das vias principais delimita células básicas (superquadras), por sua vez subdivididas em quadras menores por vias secundárias, que geram praça no interior de cada célula. Quarteirões de conformação rígida e invariável, de $318 \times 318 \mathrm{~m}$, se repetem por área de cerca de 1 milhão de metros quadrados. Os blocos, todos de $200 \mathrm{~m}$ de comprimento, são divididos em lotes iguais, e os prédios, construídos no alinhamento das ruas, sem afastamentos laterais e obedecendo ao rígido gabarito de altura. A praça do miolo do grande quarteirão, que se supõe de escala mais íntima, mede $100 \times 100 \mathrm{~m}$. Já na proposta (b) são permitidos variados miolos de quadra dotados de escala mais humana e definidos por configurações de edificações a serem posteriormente definidas por grupos de ação local, permitindo ajustes. Os chamados quarteirões híbridos estabelecem um gradiente de privacidade no arranjo do conjunto e configuram uma estrutura de caminhos variados e verdes em meio a uma diversidade tipológica, tendo o potencial de colaborar para a legibilidade dos percursos e na percepção de conjuntos de entradas. Na proposta (a), a escala, a repetitividade e comprimento excessivo dos blocos e a impossibilidade de eventuais destaques no perfil das edificações prejudicam o conceito "identidade". Na proposta (b) são permitidos destaques no perfil das edificações, além de variadas transições públicoprivado.

O projeto para a Área Jardim São Francisco (Figura 9) demonstra forte afinidade aos conceitos conectividade, legibilidade e sustentabilidade social e identidade. A implantação de UHs ora sobrepostas, ora geminadas configura conjunto integrado de espaços externos em gradiente do público ao privado, valorizando a rua como espaço de lazer e encontro, bem como a circulação de pedestres. Pequenos grupos de UHs são acessados por portais que marcam e estruturam o conjunto, conferindo orientação, legibilidade e senso de lugar, sendo reconhecidos e valorizados pelos moradores como elemento de referência e identidade. Formatos diferenciados de caminhos bem como de ambientes semiabertos ao longo dos limites também contribuem para a identidade. A sustentabilidade social revela-se ainda pela construção do conjunto por mutirão, que também incentivou um maior envolvimento da comunidade local. Este projeto é ainda exemplar do conceito "opções e flexibilidade". Oferece variações tipológicas a partir de módulos expansíveis que respeitam a escala e a organização interna e geral das Uhs, demonstrando como a racionalidade construtiva e a repetitividade podem respeitar a adequação às atividades e a necessidade de identidade. 


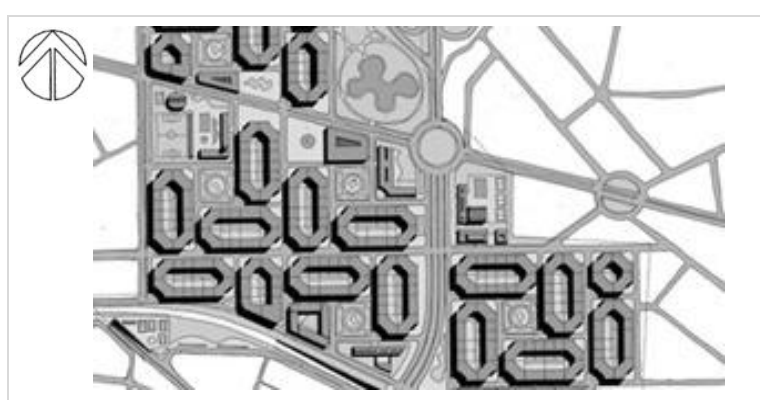

(a) $1^{\circ}$ Prêmio

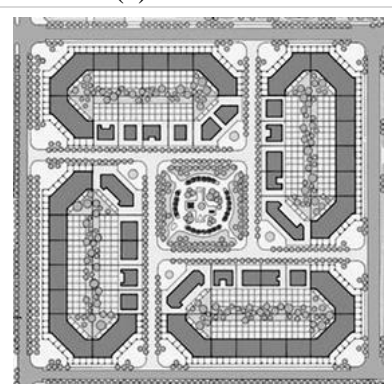

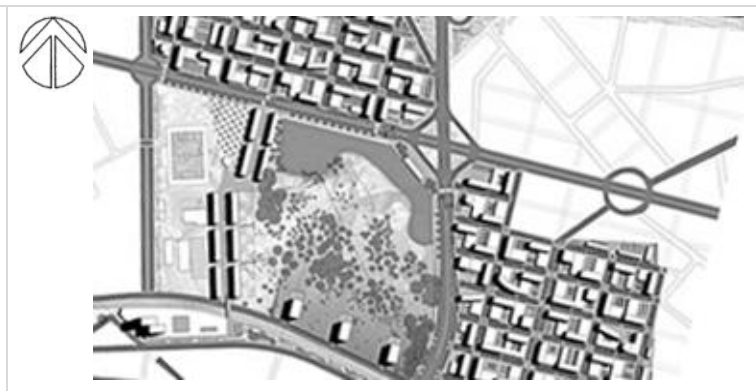

(b) $4^{\mathrm{a}}$ Menção Honrosa

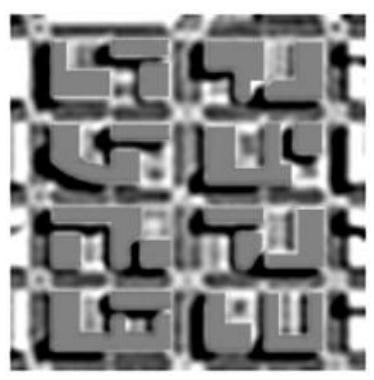

Fonte: Vitruvius (2000).

Figura 8 - Trecho da implantação e quarteirão típico: Concurso Bairro Novo
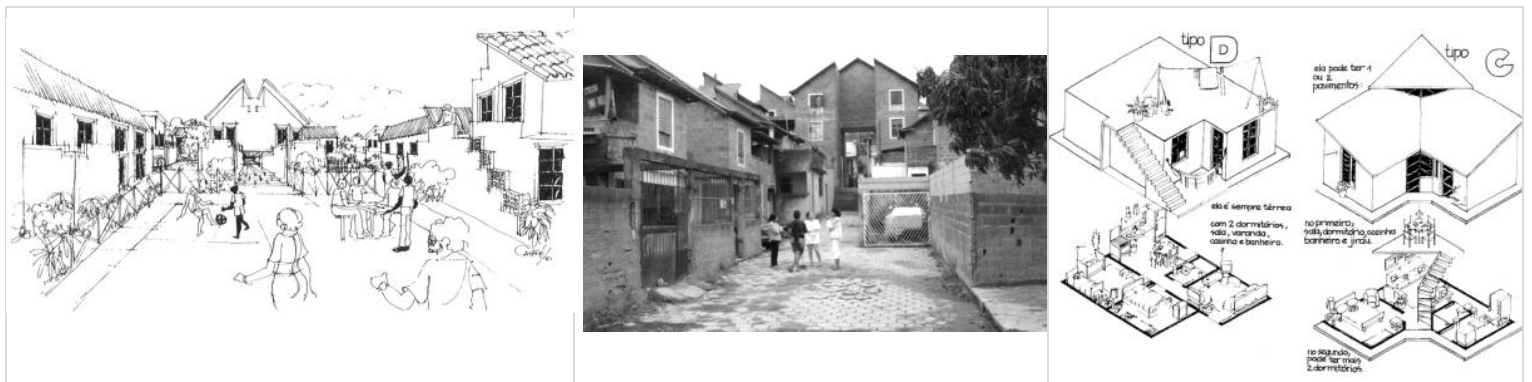

Fonte: Fonseca et al. (1990); Arquivo pessoal; Maricato (1990).

Figura 9 - Projeto Área Jardim São Francisco: Concurso Nacional de Projetos para Habitação Popular

Os conceitos humanizadores na categoria do senso de urbanidade alinham-se à argumentação de Jacobs (1961) em favor de uma vida urbana de qualidade e vitalidade. Jacobs identifica e detalha as condições indispensáveis que criam as diversas e eficientes combinações de usos, entre elas a necessidade de quadras curtas e de edifícios com idades e estados de conservação variados. Com relação à necessidade de concentração, considera as densidades habitacionais como fator de vitalidade, que, conforme esclarece cuidadosamente, não equivale à superlotação de moradias. Jacobs desestimula edifícios altos argumentando que edificações mais baixas podem facilitar a conciliação de altas densidades com a necessária variedade de construções e diversidade de usuários. Também observa como quadras muito longas podem ser opressivas, sendo necessário entrecortá-las por ruas frequentes, em prol da diversidade.
As propostas de Nikos Salingaros também estabelecem relação com os desenvolvimentos teóricos de Christopher Alexander. Salingaros et al. (2006) exploram processos e práticas para a habitação social que procuram canalizar a necessidade humana natural por ambientes enriquecedores (vivos, saudáveis) e mais sustentáveis. Os autores enfatizam, entre outros, dois aspectos que reforçam a avaliação exposta acima: o potencial definidor do espaço urbano para o caráter do assentamento como um todo e a importância da capacidade de adaptabilidade de projetos habitacionais à sensibilidade humana, que pressupõe a construção gradual e uma participação maior e efetiva dos usuários nas fases de projeto e construção.

A relação entre os conceitos humanizadores e a qualidade - sobretudo ambiental - dos projetos referidos ocorre em diferentes graus de afinidade. Em virtude da amostra de projetos em questão, considera-se que a análise ilustrativa dos projetos 
sob a ótica dos conceitos aqui exposta atesta a necessidade da busca por projetos exemplares daqueles conceitos.

\section{Considerações finais}

O trabalho apresenta abordagem para o projeto habitacional que relaciona conceitos humanizadores a sua qualidade ambiental e também sobre sua aplicação como instrumental de análise e reflexão no processo de projeto. Enfatiza-se, todavia, que o olhar analítico sobre projetos sob a abordagem humanizadora consiste de recorte específico, que certamente não esgota a análise deles.

Os conceitos para a qualidade do projeto da habitação coletiva como um todo são valorizados frisando-se a importância de sua complementaridade bem como da conexão entre os parâmetros projetuais. Os parâmetros e conceitos propostos permeiam as diferentes dimensões da sustentabilidade, com maior ênfase nas dimensões social e ambiental. Salienta-se o caráter congruente e aberto da abordagem e que as especificidades locais devem permitir e sugerir novas contribuições. Acredita-se também que a abordagem proposta adiciona-se a outras iniciativas que repensam a pesquisa e o ensino do projeto urbano-arquitetônico, incentivando a incorporação de conceitos dentro da perspectiva do desenvolvimento sustentável em prol de maior qualidade de vida humana. A espécie humana, embora protegida de mudanças ambientais pela cultura e pela tecnologia, depende fundamentalmente do fluxo dos serviços dos ecossistemas. Importante avaliação ecossistêmica do milênio coordenada pelo Programa das Nações Unidas para o Meio Ambiente examinou como as mudanças nos serviços dos ecossistemas, dos quais a cidade faz parte, influenciam a qualidade de vida e o bem-estar humano. Entende-se que o bem-estar humano seja constituído de múltiplos elementos, incluindo materiais básicos para uma vida salutar, onde a moradia se insere, saúde, boas relações sociais, segurança e liberdade de escolha e de ação, que inclui a oportunidade de se alcançar o que se almeja (MILLENNIUM ECOSYSTEM ASSESSMENT, 2006). A perda dos serviços providos pelos ecossistemas constitui uma grande barreira às metas de desenvolvimento do milênio de reduzir a pobreza, a fome e as doenças.

No contexto da habitação social, as iniciativas até o momento do programa nacional Minha Casa, Minha Vida (PMCMV), que visa suprir o déficit habitacional no país e é de largo alcance nacional, não refletem a priorização do conjunto de conceitos já reconhecido como inerente da habitação coletiva, seja pelo carater humanizador ou pelo valor multidimensional para os moradores Observa-se a padronização do projeto e sua simplista replicação no território, inclusive em áreas bastante distintas, nos moldes do programa habitacional dos anos 60 e 70, desconsiderando avaliações e pesquisas relevantes e abundantes da área e principalmente o impacto futuro nas cidades brasileiras. Parece prevalecer o interesse apenas na larga escala de intervenção dos empreendimentos, rapidez de execução e no maior lucro. Contudo, as propostas aqui apresentadas fomentam outras perspectivas para o habitar na cidade, nas quais o PMCMV pode transformar-se em oportunidade. Os conceitos verificados, avessos à abstração dos índices e coeficientes típicos da legislação urbanística e edilícia, representam qualidades morfológicas e ambientais do ambiente construído que procuram resgatar um senso de urbanidade e de habitabilidade. Apesar da proposta de Alexander et al. (1977) parecer requerer uma supressão utópica de valores econômicos em prol de valores de uso do ambiente construído, ressaltase que a consideração dos conceitos humanizadores por meio dos parâmetros de projeto pode beneficiar de forma notável o processo e a qualidade de projetos de HIS e, consequentemente, cooperar para cidades mais sustentáveis.

\section{Referências}

ALEXANDER, C. A City is Not a Tree. Design, London, n. 206, p. 44-55, Feb. 1966.

\section{ALEXANDER, C. Sustainability and}

Morphogenesis: the birth of a living world.

Berkeley: Center for Environmental Structure, 2004. Disponível em:

<www.livingneighborhoods.org/library/schumache r-v17.pdf>. Acesso em: 20 mar. 2009.

ALEXANDER, C. et al. A Pattern Language: towns, buildings, construction. New York: Oxford University Press, 1977

\section{BARROS, R. R. M. P. Habitação Coletiva: a} inclusão de conceitos humanizadores no processo de projeto. 2008. $398 \mathrm{f}$. Tese (Doutorado em Engenharia Civil) - Faculdade de Engenharia Civil, Arquitetura e Urbanismo, Universidade Estadual de Campinas, Campinas, 2008.

Disponível em:

<http://libdigi.unicamp.br/document/?code $=00043$ 4038>. Acesso em: 06 mar. 2009. 
BARROS, R. R. M. P.; PINA, S. A. M. G. Uma Abordagem de Inspiração Humanizadora para a Qualificação Espacial do Projeto de Habitação Coletiva. In: ENCONTRO NACIONAL E ENCONTRO LATINO-AMERICANO SOBRE EDIFICAÇÕES E COMUNIDADES SUSTENTÁVEIS, 5., 2009, Recife. Anais..., Porto Alegre: ANTAC, 2009a. 1 CD-ROM.

BARROS, R. R. M. P.; PINA, S. A. M. G. Uma Reflexão sobre Assentamentos Humanos Mais Sustentáveis: o projeto urbano Bairro Novo. In: ENCONTRO NACIONAL E ENCONTRO LATINO-AMERICANO SOBRE EDIFICAÇÕES E COMUNIDADES SUSTENTÁVEIS, 5., 2009, Recife. Anais..., Porto Alegre: ANTAC, 2009b. 1 CD-ROM.

BLOOMER, K.; MOORE, C. Body, Memory and Architecture. New Haven: Yale University Press, 1978.

CARMONA, M. Housing Design Quality: through policy, guidance and review. New York: Spon, 2001.

COELHO, A. B. Habitação Humanizada: TPI 46. Lisboa: LNEC, 2007.

DOVEY, K. The Pattern Language and its Enemies. Design Studies, Oxford, v. 11, n. 1, p. 39, Jan. 1990.

FERNANDES, A. Construção Compartilhada. Arquitetura e Urbanismo, São Paulo, v. 172, jul. 2008. Disponível em:

$<$ http://www.revistaau.com.br/arquiteturaurbanismo/172/artigo95912-1.asp >. Acesso em: 20 abr. 2009.

FONSECA, N. A. et al. Habitação popular: contraponto à massificação. Arquitetura e Urbanismo, São Paulo, n. 30, p. 48-62, jun./jul. 1990.

GRAUMANN, C. The Phenomenological Approach to People-Environment Studies. In: BECHTEL, R.; CHURCHMAN, A. Handbook of Environmental Psychology. New York: John Wiley \& Sons, 2000. p. 95-113.

GROAT, L.; WANG, D. Architectural Research Methods. New York: John Wiley \& Sons, 2002.

HALL, E. The Hidden Dimension. New York: Doubleday, 1966.

HESCHONG, L. Thermal Delight in

Architecture. 12. ed. Cambridge: MIT, 2002.
JACOBS, J. The Life and Death of Great American Cities. New York: Random House, 1961.

KOWALTOWSKI, D. C. C. K. Humanization in Architecture: analysis of themes through high school building problems. 1980. $152 \mathrm{f}$. Tese (Doutorado em Arquitetura) - College of Environmental Design, University of California Berkeley, 1980.

KOWALTOWSKI, D. C. C. K. et al. Quality of Life and Sustainability Issues as Seen by the Population of Low-Income Housing in the Region of Campinas, Brazil. Habitat International, Oxford, v. 30, n. 4, p. 1100-1114, 2006.

LYLE, J.T. Regenerative Design for Sustainable Development. New York: John Wyley \& Sons, 1994.

LYNCH, K. The Image of the City. Cambridge: MIT, 1960.

MARICATO, E. Habitação: uma utopia possível. Projeto, São Paulo, v. 134, p. 69-90, ago./set. 1990.

MILLENNIUM ECOSYSTEM ASSESSMENT. Global Assessment Reports: current state \& trends. Washington, DC: Island, 2006. v. 1.

NORBERG-SCHULZ, C. Heidegger's Thinking on Architecture. Perspecta, New Haven, v. 20, p. 61-68, 1983.

NORBERG-SCHULZ, C. The Phenomenon of Place. Architectural Association Quarterly, Oxford, v. 8, n. 4, p. 3-10, 1976.

PADOVANO, B. R. Concurso: criatividade de sobra. Projeto, São Paulo, v. 174, p. 70-73, maio 1994.

PROTZEN, J. The Poverty of the Pattern Language. Design Methods and Theories, San Luis Obispo, v. 12, n. 3/4, p. 191-194, Sept./Dec. 1978.

RAPOPORT, A. House, Form and Culture. Englewood Cliffs: Prentice Hall, 1969.

ROWE, P. Modernity and Housing. Cambridge: MIT, 1995.

SALINGAROS, N. The Structure of Pattern Languages. Architectural Research Quarterly, Cambridge, v. 4, n. 2, p. 149-161, 2000. 
SALINGAROS, N. et al. Habitação Social na América Latina: uma metodologia para utilizar processos de auto-organização. In: CONGRESSO IBERO-AMERICANO DE HABITAÇÃO SOCIAL, 1., 2006, Florianópolis. Anais... Florianópolis: Universidade Federal de Santa Catarina, 2006. 1 CD-ROM.

SATTLER, M. A. Habitações de Baixo Custo Mais Sustentáveis: a casa alvorada e o centro experimental de tecnologias habitacionais sustentáveis. Porto Alegre: ANTAC, 2007. (Coleção Habitare, 8). Disponível em: <www.habitare.org.br/pdf/publicacoes/arquivos/co lecao9/livro_completo.pdf $>$. Acesso em: $20 \mathrm{dez}$. 2008.
SAUNDERS, W. S. A Pattern Language (book review). Harvard Design Magazine, Cambridge, n. 16, p. 1-7, Winter/Spring 2002. Disponível em: <http://www.gsd.harvard.edu/research/publications /hdm/back/16books_saunders.html>. Acesso em: 20 dez. 2008.

SCHNEIDER, T.; TILL, J. Flexible Housing: opportunities and limits. Architectural Research Quarterly, Cambridge, v. 9, n. 2, p. 157-166, 2005.

SHERWOOD, R. Modern Housing Prototypes. 6. ed. Cambridge: Harvard University Press, 1994.

SOMMER, R. Personal Space. New Jersey: Prentice-Hall, 1969.

VITRUVIUS. Concurso Bairro Novo. São Paulo, 2000. Disponível em:

<http://www.vitruvius.com.br/revistas/read/projeto s/04.044/2398>. Acesso em: 27 jan. 2009. 